\title{
ASSESS THE AWARENESS AND ATTITUDE REGARDING PREVENTION OF CORONAVIRUS DISEASE 2019
}

\author{
SAHBANATHUL MISSRIYA MA ${ }^{1 *}$, SUHAIL HASSAN ${ }^{2}$ \\ ${ }^{1}$ Department of Nursing, College of Applied Medical Sciences, King Faisal University, Alahsa, Kingdom of Saudi Arabia. ${ }^{2}$ Department of \\ Pharmacy, Jaya College of Pharmacy, The Tamil Nadu Dr. MGR Medical University, Thiruvallur, Chennai, Tamil Nadu, India. \\ Email: shabanajalal1999@yahoo.com
}

Received: 18 March 2020, Revised and Accepted: 28 April 2020

ABSTRACT

Objective: Coronavirus disease is the first pandemic caused by a novel coronavirus. The World Health Organization announced a name for the novel coronavirus disease 2019 (COVID-19). This epidemic must stop, contain, control, delay, and reduce the impact of this virus by the people at every opportunity. Every person has the responsibility to contribute, to protect themselves, to protect others, whether in the home, the community, the health-care system, the workplace, or in the transport system. The study was aimed to assess the level of awareness and attitude regarding the prevention of novel coronavirus disease among people and to associate the knowledge level about the prevention of novel coronavirus disease with selected demographic variables of people.

Methods: A cross-sectional descriptive design was adopted. Using a convenient sampling technique, 950 samples were selected. The data were collected, analyzed in terms of both descriptive, and inferential statistics.

Results: The study results showed that among the total number of people (950) surveyed, 499 (52.6\%) were having poor knowledge, whereas 348 (36.6\%) were having an average level of knowledge and 103 (10.8\%) were showing good knowledge regarding prevention of COVID-19. Some of the people $(40.7 \%)$ had a negative attitude on the overall aspects of COVID-19 prevention.

Conclusion: The study concluded that there were inadequate awareness and poor attitude among the people about coronavirus diseases, and hence there is a need to create awareness through campaigns by public authorities and media.

Keywords: Assess, Coronavirus disease 2019, Awareness, Attitude, Prevention.

(C) 2020 The Authors. Published by Innovare Academic Sciences Pvt Ltd. This is an open access article under the CC BY license (http://creativecommons. org/licenses/by/4. 0/) DOI: http://dx.doi.org/10.22159/ajpcr.2020.v13i7.37804

\section{INTRODUCTION}

A novel coronavirus is a new strain of the infectious disease that was not previously identified in humans [1]. The virus that causes the disease first identified during an investigation into an outbreak in Wuhan, China [2]. Chinese Center for Disease Control and Prevention reported that a novel coronavirus is the causative agent of this outbreak. The disease associated with this virus is referred to as novel coronavirus disease 2019 (COVID-19) as COVID-19 [2,3]. It is an infection that causes disease in the respiratory system also can spread from person to person [4]. As per the alarming levels of spread and severity of this disease, the Director-General of the World Health Organization characterized the COVID-19 situation as a pandemic [5].

Epidemiological records in China revealed that up to $85 \%$ spread of infection from human-to-human has occurred in family clusters and that causes 2055 healthcare workers have become infected, with an absence of major nosocomial outbreaks, and some supporting evidence that some healthcare workers acquired infection in their families [6,7]. Close and unprotected exposure is required for transmission by direct contact or by contact with fomites in the immediate environment $[8,9]$.

The Saudi Arabian Ministry of Health confirmed the first new coronavirus in March 2020. There are many (37\% of the total population) foreign guest workers other residents from the Gulf countries, and the floating population participating in the Umrah program, which is also easier to spread of COVID-19 [10]. This disease must stop, contain, control, delay, and reduce the impact of this virus by the people at every opportunity. Everyone has a responsibility to understand the coronavirus disease and take measures to protect themselves and others. They should also maintain social distance and stay at home to prevent social transmission [11].

Viral shedding in patients with mild and more severe infections seems to be greatest during the early phase of disease [12]. These symptoms may appear 2-14 days after exposure depending upon the incubation period of Middle East respiratory syndrome coronaviruses [13].

The signs and symptoms of COVID-19 include fever, dry cough, and shortness of breath or difficulty breathing. Other symptoms can include tiredness, aches, runny nose, and sore throat [14]. The diagnosis will be performed by a conventional real-time polymerase chain reaction method. The best way to prevent illness is to avoid exposure of this virus. Each country should prepare to respond and assess its risk so that it implements the necessary measures on time to reduce COVID-19 transmission and to control the impacts of economics [15]. It is important to be aware of wash hands often with soap and water for at least $20 \mathrm{~s}$, especially after you have been in a public place, or after blowing your nose, coughing, or sneezing, or using hand sanitizer that contains at least $60 \%$ alcohol, and avoid close contact with people who are sick, maintain distance between people to prevent COVID-19 spread in the community in this scenario [16,17]. Therefore, the study aims to assess the level of knowledge and attitudes toward preventing new coronavirus diseases among people and to associate the knowledge with selected demographic variables.

\section{METHODS}

\section{Study design}

Cross-sectional, descriptive design was adopted to assess the awareness level and the attitude of people regarding the prevention of novel COVID-19. 


\section{Setting}

The study was conducted in the Eastern province region which has a population of 150,000 . It is the major urban area, also known as an oasis in the Eastern province of Saudi Arabia.

\section{Sampling}

Initially, 1258 samples were selected in the Eastern province region using convenient sampling techniques. After obtaining informed consent, a total of 950 interested people who had willingness were included in the study. Ethical clearance obtained from the Institutional Review Board.

\section{Data collection}

The tool includes three parts. The first part consists of demographic variables including age, sex, educational status, occupation, nationality, place of residence, and source of health information. And the second part consists of the structured knowledge questionnaire regarding COVID-19, which was developed by researchers. The third part about attitude toward COVID-19 also developed by researcher. The score interpretation for assessing knowledge was $<50 \%$ indicates poor knowledge, $50-74 \%$ indicates average knowledge and $>74 \%$ shows good knowledge. The purpose of the study was explained to the people, and their consent was obtained after providing an information sheet. The date was collected in the month of February 2020, by structured questionnaire method. After the data collection, the awareness video was shown to the people. The video was uploaded in the YouTube and the link sent to the study people.

\section{Statistical methods}

The collected information was entered in the excel sheet then transferred to Statistical Package for Social Sciences and analyzed in terms of both descriptive and inferential statistics.

\section{RESULTS}

The collected data were analyzed and tabulated for interpreting the results.

\section{Demographic variables}

The study findings showed that among 950 participants, most of them $314(33.1 \%)$ were in the age group of 20-29 years and $284(29.9 \%)$ were in the age group of 30-39 years. In the total study participants, $572(60.2 \%)$ were females and the remaining 378 (39.8\%) were males. Regarding educational status, 405 (42.6\%) were studied graduate level and others, 288 (30.3\%), were studied up to higher secondary level. Among all the participants, 379 (39.9\%) were involved in business for their occupation, 326 (34.3\%) were private employees, and 128 (13.5\%) were working under Government organization.

Regarding the nationalities of the participants, totally there were 486 (51.2\%) Saudi and remaining all 464 (48.8\%) were non-Saudis such as Indian 164 (17.3\%), Egyptian 142 (14.9), and Philippine 158 (16.6\%). The majority of the study participants, 769 (80.9\%), were residing inside the Hofuf region and 181 (19.1\%) were living in the surrounding area of the Hofuf region. About the sources of health information, 457 (48.1\%) were receiving health information from mass media and 253 (26.6\%) people received health information from healthcare workers and $142(14.9 \%)$ were receiving from the family members.

The following Table 1 is showing that the number and frequency distribution of demographic variables of the study participants.

\section{Knowledge level regarding COVID-19 prevention}

The overall knowledge level score is interpreted in Table 2. Of the 950 participants, 499 (52.6\%) were having poor knowledge, whereas 348 (36.6\%) were having an average level of knowledge and 103 (10.8\%) were having good knowledge.

The overall mean score and standard deviation of different level of knowledge regarding the prevention of COVID-19 were for good knowledge 81.4 and 4.77, for an average knowledge 62.73 and 7.04 and for poor knowledge 29.03 and 10.39 , respectively. Table 3 is depicting the mean score and standard deviation of different level of knowledge about COVID-19 prevention.

\section{Attitude regarding COVID-19}

Attitudes are evaluated by structured tools and involve eight questions. Each of the questions was differentiated with a positive or negative attitude. A score of 1 was given to positive while 0 was given to negative attitudes with a score range of a minimum of 0 to a maximum of 8 .

Among the total participants (950), about 698 (73.5\%) were answered "yes," who were having a positive attitude for the question "Do you think that COVID-19 can get cured?" and 252 (26.5\%) were answered "no," who was having a negative attitude. Around 583 (61.4\%) people were not ready to inform to the health-care sector, if they once found that anyone of their family member gets COVID-19, due to the fear of isolation.

Table 1: Frequency distribution of demographic variables

\begin{tabular}{|c|c|c|}
\hline S. No. & Demographic variables & F (\%) \\
\hline \multirow[t]{5}{*}{1.} & Age & \\
\hline & 20-29 years & $314(33.1)$ \\
\hline & $30-39$ years & $284(29.9)$ \\
\hline & $40-49$ years & $236(24.8)$ \\
\hline & 50 and above & $116(12.2)$ \\
\hline \multirow[t]{3}{*}{2.} & Gender & \\
\hline & Male & $378(39.8)$ \\
\hline & Female & $572(60.2)$ \\
\hline \multirow[t]{5}{*}{3.} & Educational status & \\
\hline & Primary level & $32(3.4)$ \\
\hline & High school level & $225(13.2)$ \\
\hline & Higher secondary & $288(30.3)$ \\
\hline & College and others & $405(42.6)$ \\
\hline \multirow[t]{5}{*}{4.} & Occupation & \\
\hline & Unemployed & $117(12.3)$ \\
\hline & Government workers & $128(13.5)$ \\
\hline & Private workers & $326(34.3)$ \\
\hline & Business & 379 (39.9) \\
\hline \multirow[t]{5}{*}{5.} & Nationality & \\
\hline & Saudi & $486(51.2)$ \\
\hline & Indian & $164(17.3)$ \\
\hline & Egyptian & $142(14.9)$ \\
\hline & Philippine & $158(16.6)$ \\
\hline \multirow[t]{3}{*}{6.} & Place of residence & \\
\hline & Inside Hofuf area & 769 (80.9) \\
\hline & Surroundings of Hofuf & $181(19.1)$ \\
\hline \multirow[t]{5}{*}{7.} & Sources of health information & \\
\hline & Mass media & $457(48.1)$ \\
\hline & Family members & $142(14.9)$ \\
\hline & Friends & $98(10.4)$ \\
\hline & Healthcare workers & $253(26.6)$ \\
\hline
\end{tabular}

F: Frequency; \%: Percentage; $n=950$

Table 2: Knowledge level regarding coronavirus disease 2019

\begin{tabular}{lll}
\hline S. No. & Knowledge Level & F (\%) \\
\hline 1. & Good knowledge & $103(10.8)$ \\
2. & Average knowledge & $348(36.6)$ \\
3. & Poor knowledge & $499(52.6)$ \\
\hline
\end{tabular}

F: Frequency; \%: Percentage; $\mathrm{n}=950$

Table 3: Mean and standard deviation of knowledge level regarding coronavirus disease 2019

\begin{tabular}{llll}
\hline S. NO. & Knowledge level & Mean score & SD \\
\hline 1. & Good knowledge & 81.40 & 4.77 \\
2. & Average knowledge & 62.73 & 7.04 \\
3. & Poor knowledge & 29.03 & 10.39 \\
\hline M: Mean; SD: Standard Deviation; $n=950$ & &
\end{tabular}


Table 4: Attitude regarding coronavirus disease 2019

\begin{tabular}{|c|c|c|c|}
\hline S. No. & Attitude items & Response & F (\%) \\
\hline \multirow[t]{2}{*}{1.} & \multirow[t]{2}{*}{ Do you think that COVID-19 can get cured? } & Yes & $698(73.5)$ \\
\hline & & No & $252(26.5)$ \\
\hline \multirow[t]{2}{*}{2.} & \multirow{2}{*}{$\begin{array}{l}\text { Will you inform to health-care sector if you found that anyone of your } \\
\text { family members has COVID-19? }\end{array}$} & Yes & $367(38.6)$ \\
\hline & & No & $583(61.4)$ \\
\hline \multirow[t]{2}{*}{3.} & \multirow[t]{2}{*}{ If you get any symptoms of COVID-19, will you go to hospital? } & Yes & $462(48.6)$ \\
\hline & & No & $488(51.4)$ \\
\hline 4. & If you are getting COVID-19, will you accept isolation in health facilities? & Yes & $569(59.9)$ \\
\hline \multirow[t]{2}{*}{5.} & \multirow{2}{*}{$\begin{array}{l}\text { Do you think transmission of COVID-19 can be prevented by washing } \\
\text { hands with soap frequently? }\end{array}$} & Yes & $916(96.4)$ \\
\hline & & No & $34(3.6)$ \\
\hline \multirow[t]{2}{*}{6.} & \multirow[t]{2}{*}{ If COVID-19 vaccine is available, will you ready to avail it? } & Yes & $328(34.5)$ \\
\hline & & No & $622(65.5)$ \\
\hline \multirow[t]{2}{*}{7.} & \multirow[t]{2}{*}{ Do you think stay at home is going to control spread of COVID-19? } & Yes & $659(69.3)$ \\
\hline & & No & $291(30.6)$ \\
\hline \multirow[t]{2}{*}{8.} & \multirow{2}{*}{$\begin{array}{l}\text { Do you think wearing mask helpful to prevent the transmission of } \\
\text { COVID-19? }\end{array}$} & Yes & $512(53.9)$ \\
\hline & & No & $438(46.1)$ \\
\hline
\end{tabular}

F: Frequency; \%: Percentage; n=950. COVID-19: Coronavirus disease 2019

Most of the participants, 916 (96.4\%) participants, answered that the transmission of COVID-19 can be prevented by washing hands with soap frequently which shows their positive attitude. Furthermore, 622 (65.5\%) people were answered "no" for the question, if the COVID-19 vaccine is available, will you ready to avail it. This shows that people have a negative attitude on vaccination for COVID-19 because of poor confidence. Among all, 659 (69.3\%) people believed that stay at home helps to control the spread of COVID-19 and 512 (53.9\%) told that wearing masks helpful to prevent the transmission of COVID-19. Around $40.7 \%$ had a negative attitude on the overall aspects of COVID-19 prevention (Table 4).

There was a statistically significant association between the educational status and source of health information with the knowledge regarding the prevention of novel coronavirus disease at $\mathrm{p}<0.01$ and $\mathrm{p}<0.05$, respectively.

\section{DISCUSSION}

Tracing the epidemiologic character of COVID-19 will provide an understanding of the immunity of the disease. It is important to know that, in any form of outbreaks of infectious diseases, the casefatality ratio is usually incorrectly estimated at an early stage because the detection of morbidity will be biased [18]. Human behavior is influenced by people's knowledge and attitude [19]. This communitybased cross-sectional study was conducted to identify the awareness level by assessing the knowledge and attitude on the prevention of novel coronavirus. According to the present study, the results showed the overall knowledge about COVID-19 among the participants was low, as only $10.8 \%$ were showing good knowledge.

The systemic review and meta-analysis evidenced that from the previous reports and study results, pre-existing hypertension, cardiovascular diseases, persons with chronic kidney diseases, and diabetes people are highly and severely affected with COVID-19 and their prognosis will be very poor [20].

Another online cross-sectional survey was conducted to assess the knowledge, attitudes, and practices toward COVID-19 among Chinese residents during the rapid rise of COVID-19. The study resulted that the mean knowledge score was 10.8 with a standard deviation score 1.6, range between 0 and 12, suggesting an overall $90 \%$ correct rate on this knowledge test which is supported by the present study [21]. In the current study, the mean score and standard deviation of knowledge level regarding COVID-19 were for good knowledge 81.4 and 4.77, for average knowledge 62.73 and 7.04 as well for poor knowledge 29.03 and 10.39 , respectively.

The knowledge scores were significantly differed across genders, agegroups, categories of marital status, education levels, and residence places $(\mathrm{p}<0.001)$ [21]. There was a statistically significant association between the educational status and the knowledge regarding the prevention of novel coronavirus disease at $p<0.05$. These findings of the demographic factors associated with knowledge toward COVID-19 are generally consistent with previous studies on the severe acute respiratory syndrome in 2003 [22-25].

The health promotion profession can lead this charge and advocate for a national public health social media campaign and other pragmatic measures that reach people most in need. This will help support them to get accurate and timely information to prepare and reduce the risk to themselves, their families, friends, and their community [26-28].

This study has some limitations. First and foremost, the participants were selected by convenience, not by randomization. Hence, the study findings cannot be generalized. Second, the tool was translated into Arabic version for Arabic speakers and English version for non-Arabic speakers, which may have a bias in the results.

\section{CONCLUSION}

In general, most people need to have a correct understanding of COVID-19, especially in prevention and infection control measures. People attitude also needs to be changed toward positivity through arranging health campaigns by public health authorities and the media. In addition to that, ensure the people focus their attention on prevention measures such as keep social distancing and avoid crowds in malls and parks. Stay at home methods are most effective during this pandemic situation.

\section{AUTHORS' CONTRIBUTIONS}

Dr. Sahbanathul Missiriya carried out the data collection and analyzing the results of the study, whereas Suhail Hassan reviewed the literature and wrote the manuscript. Both the authors read and approved the final version of the manuscript.

\section{CONFLICTS OF INTEREST}

The authors declare that they have no conflicts of interest in publishing this article.

\section{AUTHORS' FUNDING}

The authors themselves bear the publication fees of this paper.

\section{REFERENCES}

1. Hsue B, Hartshorne T, Masters PS. Characterization of an essential RNA secondary structure in the 3' untranslated region of the murine coronavirus genome. J Virol 2000;74:6911-21. 
2. Zhu N, Zhang D, Wang W, Li X, Yang B, Song J, et al. A novel coronavirus from patients with pneumonia in China, 2019. N Engl J Med 2020;382:727-33

3. Macjkenzie JS, Smith DW. COVID-19: A novel zoonotic disease caused by a coronavirus from China: What we know and what we don't. Microbiol Aust 2020;41:45-50.

4. Chen Y, Cai H, Pan J, Xiang N, Tien P, Ahola T, et al. Functional Screen reveals SARS coronavirus nonstructural protein nsp14 as a novel cap N7 methyltransferase. Proc Natl Acad Sci U S A 2009;106:3484-9.

5. Kar SK, Arafat SM, Sharma P, Dixit A, Marthoenis M, Kabir R. COVID-19 pandemic and addiction: Current problems and future concerns. Asian J Psychiatr 2020;51:102064.

6. Wu Z, McGoogan JM. Characteristics of and important lessons from the coronavirus disease 2019 (COVID-19) outbreak in China: Summary of a report of 72314 cases from the Chinese center for disease control and prevention. JAMA 2020;323:1239-42.

7. Chan JF, Yuan S, Kok K, To KK, Chu H, Yang J, et al. A familial cluster of pneumonia associated with the 2019 novel coronavirus indicating person-to-person transmission: A study of a family cluster. Lancet 2020;395:514-23.

8. Rothe C, Schunk M, Sothmann P, Bretzel G, Froeschl G, Wallrauch C, et al. Transmission of 2019-nCoV infection from an asymptomatic contact in Germany. N Engl J Med 2020;382:970-1.

9. Yu P, Zhu J, Zhang Z, Han Y, Huang L. A familial cluster of infection associated with the 2019 novel coronavirus indicating possible personto-person transmission during the incubation period. J Infect Dis 2020;221:jiaa077.

10. Ebrahim SH, Memish ZA. COVID-19: Preparing for superspreader potential among Umrah Pilgrims to Saudi Arabia. Lancet 2020;395:e48.

11. Achonu C, Laporte A, Gardam MA. The financial impact of controlling a respiratory virus outbreak in a teaching hospital: Lessons learned from SARS. Can J Public Health 2005;96:52-4.

12. Bedford J, Enria D, Giesecke J, Heymann DL, Ihekweazu C, Kobinger G, et al. COVID-19: Towards controlling of a pandemic. Lancet 2020;395:1015-8

13. Algaissi A, Alharbi N, Hassanain M, Hashem A. Preparedness and Response to COVID-19 in Saudi Arabia: Lessons Learned from MERSCoV. Basel: Preprints; 2020.

14. Sudan P, Goswami M, Babu MA. Novel coronavirus (COVID-19)-a critical review. Int J Res Pharm Sci 2020;11:43-7.

15. Gaunt ER, Hardie A, Claas EC, Simmonds P, Templeton KE.
Epidemiology and clinical presentations of the four human coronaviruses 229E, HKU1, NL63, and OC43 detected over 3 years using a novel multiplex real-time PCR method. J Clin Microbiol 2010;48:40-7.

16. Parameshwar K, Pamu S, Sandeep K, Suresh C. A review novel coronavirus. Asian J Pharm Clin Res 2020;13:12-7.

17. Brende B, Farrar J, Gashumba D, Moedas C, Mundel T, Shiozaki Y, et al. CEPI-A new global R\&D organisation for epidemic preparedness and response. Lancet 2017;389:233-5.

18. Wang C, Horby PW, Hayden FG, Gao GF. A novel coronavirus outbreak of global health concern. Lancet 2020;395:470-3.

19. Shah NM, Rahim MA. Parental knowledge, attitudes and practices (KAPS) on the use of antibiotics in children for upper respiratory tract infections (URTIS). Int J Pharm Pharm Sci 2017;9:105-10.

20. Wang X, Fang X, Cai Z, Wu X, Gao X, Min J, et al. Comorbid chronic diseases and acute organ injuries are strongly correlated with disease severity and mortality among COVID-19 patients: A systemic review and meta-analysis. Research (Wash D C) 2020;2020:2402961.

21. Zhong BL, Luo W, Li HM, Zhang QQ, Liu XG, Li WT, et al. Knowledge, attitudes, and practices towards COVID-19 among Chinese residents during the rapid rise period of the COVID-19 outbreak: A quick online cross-sectional survey. Int J Biol Sci 2020;16:1745-52.

22. Zhang X, Sun Y, Ye D, Sun Z, Su H, Ni J, et al. Analysis on mental health status of community residents in Hefei during SARS spread. Chin J Dis Contr Prev 2003; 7:280-2.

23. Jiao J, Tang X, Li H, Chen J, Xiao Y, Li A, et al. Survey of knowledge of villagers in prevention and control of SARS in Hainan Province. Chin Trop Med 2005;5:703-5.

24. Zou L, Ruan F, Huang M, Liang L, Huang H, Hong Z, et al. SARS$\mathrm{CoV}-2$ viral load in upper respiratory specimens of infected patients. $\mathrm{N}$ Engl J Med 2020;382:1177-9.

25. Kim JY, Ko JH, Kim Y, Kim YJ, Kim JM, Chuna YS. Viral load kinetics of SARS-CoV-2 infection in first two patients in Korea. J Korean Med Sci 2020;35:e86.

26. Smith JA, Judd J. COVID-19: Vulnerability and the power of privilege in a pandemic. Health Promot J Aust 2020;31:158-60.

27. Akunne MO, Chukwueke UC, Anosie C. Assessment of knowledge of Zika virus infection among health care professionals in a Southeastern State of Nigeria. Int J Pharm Pharm Sci 2018;10:56-60.

28. Sauriasari R, Apriyanti YF, Pramono D. Assessment of antibiotic prescription in patients with non-pneumonia acute respiratory tract infection. Int J Appl Pharm 2018;10:66-9. 